\title{
The Phenomenology of "Pure" Consciousness as Reported by an Experienced Meditator of the Tibetan Buddhist Karma Kagyu Tradition. Analysis of Interview Content Concerning Different Meditative States
}

\author{
Cyril Costines ${ }^{1, * \mathbb{D}}$, Tilmann Lhündrup Borghardt ${ }^{2}$ and Marc Wittmann ${ }^{3}$ (D) \\ Department of Philosophy, Johannes Gutenberg University Mainz, 55122 Mainz, Germany \\ The Ekayana Institute, 79853 Lenzkirch, Germany; tilmann.borghardt@gmx.de \\ Institute for Frontier Areas of Psychology and Mental Health, 79098 Freiburg, Germany; wittmann@igpp.de \\ * Correspondence: costines@uni-mainz.de
}

Citation: Costines, C.; Borghardt, T.L.; Wittmann, M. The Phenomenology of "Pure" Consciousness as Reported by an Experienced Meditator of the Tibetan Buddhist Karma Kagyu Tradition. Analysis of Interview Content Concerning Different Meditative States. Philosophies 2021, 6, 50. https://doi.org/10.3390/ philosophies6020050

Academic Editor: Marcin J. Schroeder

Received: 15 April 2021

Accepted: 4 June 2021

Published: 17 June 2021

Publisher's Note: MDPI stays neutral with regard to jurisdictional claims in published maps and institutional affiliations.

Copyright: (c) 2021 by the authors. Licensee MDPI, Basel, Switzerland. This article is an open access article distributed under the terms and conditions of the Creative Commons Attribution (CC BY) license (https:// creativecommons.org/licenses/by/ $4.0 /)$.

\begin{abstract}
A philosopher and a cognitive neuroscientist conversed with Buddhist lama Tilmann Lhündrup Borghardt (TLB) about the unresolved phenomenological concerns and logical questions surrounding "pure" consciousness or minimal phenomenal experience (MPE), a quasi-contentless, non-dual state whose phenomenology of "emptiness" is often described in terms of the phenomenal quality of luminosity that experienced meditators have reported occurs in deep meditative states. Here, we present the excerpts of the conversation that relate to the question of how it is possible to first have and later retrieve such non-dual states of selflessness and timelessness that are unrelated to sensory input. According to TLB, a "pure" experience of consciousness contains the phenomenal quality of luminous clarity, which is experienced solely in the transitional phase from the non-dual state of absolute emptiness to the state of minimal emptiness, when the person gradually returns to duality. However, this quality of luminous clarity can also be experienced in non-minimal states as in the experiential mode of being awakened. TLB describes this transition as a kind of ephemeral afterglow in the form of a maximally abstract phenomenal quality, i.e., luminosity, which justifies the conclusion of having been in a state of "pure" consciousness.
\end{abstract}

Keywords: consciousness per se; pure awareness; pure consciousness; minimal phenomenal experience; content-free awareness; dharmakāya; mahāmudrā; fMRI; EEG

\section{Introduction}

This paper explores "pure", "contentless" consciousness, in particular its phenomenology of "emptiness". A decade ago, Thomas Metzinger [1] raised the following rhetorical questions, but scholars working in the field of philosophical and empirical consciousness research have only recently begun to explore topics that were once academically neglected, such as "pure" consciousness:

It has long been known that in deep meditation the experience of unity and holistic integration is particularly salient. Thus, if we want to know what consciousness is, why not consult those people who cultivate it in its purest form? Or even better, why not use our modern neuroimaging techniques to look directly into their brains while they maximize the unity and holism of their minds? [1]

In July 2018, Cyril Costines (CC) and Marc Wittmann (MW) visited the Buddhist lama Tilmann Lhündrup Borghardt (TLB) at the Ekayana Institute in Lenzkirch, Germany, a meditation center in the Black Forest, to discuss unresolved phenomenological concerns and logical questions related to "pure" consciousness. It has been repeatedly questioned whether such a contentless, and thus selfless, state can be experienced or reported by 
anyone at all, and whether phenomenological testimonies by practitioners who claim to have been in such a state are merely retrospective confabulations.

In Section 2, we provide a brief theoretical framework focusing on Thomas Metzinger's [2,3] conceptualization and naturalization of "pure" consciousness as minimal phenomenal experience (MPE), and this is followed by a brief review of empirical data on "pure" consciousness in Section 3. Section 4 contains a translated excerpt from our phenomenological interview with TLB, conducted in German. Section 5 explicates the interview and enriches it for better understanding with additional phenomenological comments that place it in the larger context of meditation and consciousness. In this context, corresponding descriptions and analyses will not only be phenomenological but will also be carried out on a representational and neuroscientific level whenever necessary.

\section{Theoretical View of "Pure" Consciousness}

Consciousness per se, i.e., the structural invariance of phenomenal experience, which is independent of the constantly changing phenomenal content, can be addressed by describing and analyzing minimal phenomenal experience. Minimal consciousness has become an increasingly important subject of philosophical and empirical research on consciousness because its study contributes to the identification of the minimal neural correlate of consciousness. Consciousness per se, as the "essence" of consciousness, trivially underlies all global states in multidimensional state space (see [4]). According to Metzinger [1], this "essence" of consciousness can also be instantiated as a sui generis MPE, i.e., it is a type of state that is distinct from other states of consciousness such as ordinary, pathological, or experimentally induced altered states of consciousness (ASC) or dream states (see $[5,6])$, but which inherently share this invariant structure to be what they are in the first place: states of consciousness. Consciousness per se is a transcendental condition for the possibility of all other states, is functionally integrated into them, and can be instantiated independently of them as MPE. Khachouf et al. [7] have argued that intentionality, coessential with pre-reflexive self-consciousness, is the a priori invariant structure of consciousness or transcendental core of consciousness. "Pure" consciousness refers to a noema-suspended noesis of a kind that, to count as experience at all, must necessarily be phenomenal but which does not instantiate intentional properties. "Pure," "contentless" consciousness is phenomenal but non-intentional or non-representational. A broad conceptualization of intentionality is that mental states have the property of referring to something and that conscious experience is directed toward an object [8-10]. A representation is an intramental process that depicts an intentional object [11]. The questions now are as follows: Can phenomenal content exist in the absence of intentional content? Is phenomenality per se dissociable from intentionality per se? If "pure" consciousness is said to be both contentless and purposeless, does the synonymous expression that it is "consciousness of consciousness," understood as the experience of consciousness per se, make sense?

While some philosophers have argued for the impossibility of being in a state of pure consciousness because it is not possible to be conscious without being conscious of something [12,13], others have argued that MPE is not ruled out by phenomenological considerations [3,14], and that we might even find empirical evidence for MPE. This paper allows a better understanding of the invariant phenomenal structure of consciousness based on an in-depth discussion with TLB on MPE.

Traditionally, MPE refers to a non-egoic, wakeful state without intentional content, a form of phenomenal "emptiness" or "nothingness" [15-17]. Recent efforts to understand "pure" consciousness characterize it in terms of several phenomenological dimensions, including, for example, epistemicity, bliss, luminosity, and continuity $[3,18,19]$. Highly experienced meditators such as TLB describe having a "mystical" feeling of sheer "structural emptiness" during deep meditation, accompanied by timelessness, selflessness, blissful awareness, and self-luminosity. 
As Millière [20] discusses, a phenomenal self ${ }^{1}$ is not necessary for consciousness, and certain altered states of consciousness states might be totally selfless. On a phenomenological level, MPE is characterized by the absence of a phenomenal self or a minimal phenomenal self-understanding in the sense of self-identification as a transparent spatialporal self-location $[23,24]$, not even a rudimentary subjective experiential perspective [11]. $\mathrm{MPE}$ is non-agentive; i.e., there is no phenomenal self-representation as a cognitive agent possessing subjective preferences [3]. The phenomenology of MPE is characterized by the absence or a minimum of complexity of a superimposed spatiotemporal structure of phenomenality ("structural emptiness"), while the mere phenomenal field is experienced as "self-luminous". Interestingly, similar phenomenological reports are found in people with ecstatic epilepsy who describe the phenomenal content they experienced prior to their loss of consciousness [25].

During such a selfless state, perceptual or memory data are supposedly not available for phenomenal representation or cannot be integrated into autobiographical memory, as this requires a phenomenal self-model [11]. If accessible data have been either minimized or eliminated from representational space or phenomenal representation, then how can they be experienced and reported as "emptied reference?"

Paradoxically, the ability to retrospectively report a selfless state presupposes the instantiation of an autobiographical self-model during that state, while its instantiation is a condition of impossibility for that state. A fruitful research strategy for investigating the epistemic target, namely, the structural invariance of consciousness, is to examine the transitional configuration of consciousness at the threshold between the experience of absence and the absence of experience.

In this context, four fundamental questions need to be addressed: (1) What is the simplest, maximally abstract phenomenal quality that a conscious system can instantiate? (2) Is this quality always instantiated when a system is conscious? (3) Is it possible to instantiate this quality without instantiating any other phenomenal qualities? (4) Is this quality reportable when a system is conscious?

Possible candidates for the simplest, maximally abstract phenomenal quality are "selfluminosity" or "epistemicity" [2,3], which are also mentioned in TLB's phenomenological accounts.

What epistemological value does the study of MPE have for a philosophically and empirically informed theory of consciousness?

There is [...] a certain form of consciousness, one that I name consciousness, which exists as form of consciousness next to others, but as an ingredient for those others entails that they are forms of consciousness at all. That has to be examined more closely. [translated from German by MW] [26] (p. 10)

If it is true that MPE, as the closest possible instantiation of consciousness per se is inherent in all states, then the functional integration of the correlate of MPE across all global states of consciousness can be postulated with high plausibility, which can further the development of a unified, coherent, and integrated theory of consciousness.

Assuming that the causal influence of the ARAS (Ascending Reticular Arousal System) signal is maximally distributed and causally enables all forms of global states encompassed by the multidimensional state space, and that the ARAS model represents its hidden cause, the corresponding phenomenology of emptiness should be omnipresent and implicitly underlie all other forms of consciousness. MPE as a continuously instantiated, "contentless"

\footnotetext{
1 The term "phenomenal self" refers to an epistemic subject's awareness of itself-also called "sense of self," "self-awareness," or "self-consciousness." According to Metzinger's Self-Model Theory of Subjectivity [11,21], no one is or has a self; rather, a conscious representational system instantiates a transparent phenomenal self-model whose content is the phenomenal self (e.g., sensations, emotions, memories, thoughts, acts of will). Non-ordinary forms or absence of the phenomenal self can be conceptualized as a result of deviant self-modeling and can occur spontaneously under both non-pathological and pathological conditions or be induced by pharmacological as well as non-pharmacological methods [22]; meditation as practiced by TLB would be an example of the latter.
} 
state of consciousness, as postulated by Metzinger's preliminary ARAS model theory (AMT), may be necessary to explain the continuity of conscious experience [27].

According to Metzinger's AMT [2], MPE can be described and analyzed as an internal representation of the current and expected level of cortical arousal and as a dynamic predictive model that serves to control and regulate the global signal global signal of the ARAS, which in turn is essential for the emergence of consciousness. Metzinger's profound (metaphysical) claim of identity is as follows: "Pure" consciousness, or the "essence" of consciousness, is the ARAS model. MPE as the minimal form of phenomenal experience is a predictive top-down model of the autoactivating bottom-up ARAS signal [2].

But what exactly is the relationship of the neurophysiologically implemented ARAS model to consciousness per se? Interestingly, this question amounts to a more subtle variant of the "Gretchenfrage" ${ }^{2}$ of consciousness research, often referred to as the mind-body problem [28] or the hard problem of consciousness [29], and it is precisely this variant that in its simplicity strikes at the deepest core of the conundrum that lies at the boundary between subpersonal and personal levels.

Clearly, a discussion of phenomenal experience and brain states would sooner or later be confronted with the "Gretchenfrage", the crucial question, which, from a historical perspective, has been addressed by a variety of approaches ranging from denial of the existence of consciousness to the monistic reduction of consciousness to matter and vice versa to dualistic conceptualizations. Although this is not the place to provide a detailed discussion of all available avenues, it is worth pointing out that they remain the subject of controversy both in consciousness research and in many contemplative traditions.

For example, the Dalai Lama has pointed out that there may be no neural correlates for "pure" consciousness:

Now I'd like to say more about the fundamental nature of the mind. There is no reason to believe that the innate mind, the very essential luminous nature of awareness, has neural correlates, because it is not physical, not contingent upon the brain. So while I agree with neuroscience that gross mental events correlate with brain activity, I also feel that on a more subtle level of consciousness, brain and mind are two separate entities. [30]

But why should "pure" consciousness lack an underlying neural substrate? Should we not rather assume that "pure" consciousness, like all other experiences, is hardwired? In light of both philosophical theories and empirical evidence from various disciplines and non-Western traditions of thought, we attempt to triangulate MPE, a state that is neither deep sleep nor loss of consciousness. Terms like "self-luminosity" or "ARAS model" remain theoretical placeholders that need to be enriched empirically and semantically and that open up the doors for a number of future research projects (see the MPE Project [31]). Further research is needed to develop a deeper understanding regarding the fundamental aspect of arousal for consciousness per se. For instance, Metzinger's AMT does not take into account that "pure" consciousness can have different degrees of arousal. Recently, Josipovic and Miskovic [19] have argued that consciousness per se is primarily a kind of awareness that is non-conceptual, non-propositional, and non-dual, i.e., non-representational, which would not be adequately described by the two-dimensional AMT in terms of arousal and phenomenal content.

Metzinger's AMT is in the initial theory-genetic phase of constraining and describing the epistemic target phenomenon and introducing new conceptual tools. Whether the AMT will prevail depends on whether it can withstand rigorous empirical research.

\section{Neurophysiological View on "Pure" Consciousness during Deep Meditation}

The neural correlates of the minimal phenomenal state have not yet been convincingly identified. An extraordinarily experienced meditator of the Tibetan Buddhist Karma Kagyü tradition, TLB, who has been meditating for over 40 years, recently reported to have been

2 A question that goes right to the core of a problem and usually has a difficult answer. 
in a state of content-free awareness while meditating during an EEG-fMRI recording [32]. A conversation with TLB in March 2014 indicated that he had already had more than $50,000 \mathrm{~h}$ of meditation practice. While living as an ordained monk in France for 10 years, he meditated $12 \mathrm{~h}$ daily (for the conversation, see [33]). As a trained medical doctor, TLB is an ideal subject for studies of neurophenomenology, as he understands the scientific third-person perspective when he reports his first-person experience. He has participated in several single-case studies in Stefan Schmidt's lab at the University Clinic Freiburg for several years [34].

In the most recent study, TLB attended a neurophysiological recording session at the Department of Radiology at the University Medical Center in Freiburg [32]. The following research protocol was applied: During an initial $5 \mathrm{~min}$ baseline run (a run is a specific data acquisition period), he was asked to stay relaxed and alert without engaging in any formal meditation practice. In the following 3 min runs, he was requested to focus on external sensory perceptions, internal mentation, and, finally, his bodily sensations. Then, he was requested to engage in formal meditation for $30 \mathrm{~min}$ to reach a state of contentfree awareness. After each run, he provided self-ratings of his mental content on visual analogue scales with answer categories ranging from 1 to 10 presented on a touchpad.

In the baseline condition, TLB rated the amount of mental content, the intensity of his physical self-awareness, and his experience of time and space all between 8 and 9 on the 10-point scales. The 30 min meditation period was rated 2 for sensory perceptions and images and bodily self-awareness and 1 for his experience of time and space. In a follow-up interview conducted by Ulf Winter right after the scan, he reported having had no awareness of any mental content or any sensory event (this includes the noise of the scanner) during the final phase of meditation. He also had no experience of self, time, or space. The loss of the sense of time, space, and self are typical of altered states of consciousness [33,35] and have been reported after states of deep meditation [36-39]. Borghardt reported having been awake the whole time (the EEG data did not show typical sleep-related neural patterns). He felt deeply refreshed after meditation and considered this to be a sign of attaining a deep state of non-dual consciousness. In terms of Tibetan Buddhism, TLB classified this experience of basic mahāmudrā as an absolute openness without any activation of the senses.

The neural correlates of the meditation period recorded with high-resolution EEG and ultrafast fMRI showed a substantial decrease in alpha power, an increase in theta power (EEG recording), an increase in functional connectivity in the dorsal attention network, and a decrease in the posterior default-mode network (fMRI recording). The increase in connectivity within the dorsal attention network together with the increase in theta power may have been due to an increased stable attentional state disconnected from sensory processes. The reduced connectivity within the posterior default-mode network along with the decreased alpha power could be attributed to a loss of self-related mentation processes, which possibly form components of the neural correlate of consciousness per se.

\section{In-Depth Conversation about "Pure" Consciousness}

MW-01: \{Reading a quotation by TLB in the book Altered States of Consciousness: Experiences out of Time and Self [33] (p. 66)\} "Timeless awareness during meditation is an awakening. It has neither beginning nor end. This timeless time is plunging into a being in which no comparison takes place. Comparisons always involve relationships between before and after. It is timeless presence without a sense of self, without observers. Perception and perceiver are one. It is about merging into the visual or auditory impression. You lose yourself in hearing and seeing, as the experience of hearing and seeing needs no observer, no self."

TLB-01: This is about how a Buddha, an awakened person, perceives without an ego-identification, i.e., no sense of subject or self. How does communication take place? How does seeing, hearing, etc. take place in contact with the 
world, and how can communication take place without an ego being present to communicate?

MW-02: A person who has not had this experience—or the analytical philosopherhas a problem with such a statement.

TLB-02: Yes, because the philosopher makes premises. He assumes-that is the devilish thing about language - that there must be a perceiver when the verb "to perceive" is used. The same applies to walking, seeing, etc. No sense of self is necessary to be able to perceive, see, feel, and communicate. One doesn't need the sense of a center of the universe for these processes to be possible. But since we use words that all have this object reference, like "observe" and "experience", one always has the feeling that s/he must ask, "Who experiences what?" This feeling arises permanently. Language has a dualistic structure and gives us the feeling that the experience must be centered upon a supposed subject. In its research, philosophy must first detach itself from this premise and then observe the phenomenon.

CC-01: You just mentioned or implied intentional objects, or their absence in everyday experience, or better: intentionality, that is, the directedness of experience or the lack of it. You also touched on the sense of being someone and on communication in everyday life. I would prefer to first concentrate on the phenomenology of emptiness during meditation, namely a non-egoic experience of absolute non-distantiality in which no phenomenal distinctions per se are present. What you described was rather an experience of selflessness in the context of ordinary everyday life.

TLB-03: I have already gone one step further. The basic experience of awakening is initially an experience without relating to sensory perception. This is referred to as pure dharmakāya. Dharmakāya is a Sanskrit expression which describes the non-dual dimension of consciousness. The dharmakāya describes the wide, open aspect of consciousness in which nothing has yet been formed. It is the open, fundamental space that itself is dynamic and vital. It is referred to as the 'foreign body', but is only perceived per se if it is at least bound to a certain configuration, a luminosity, which becomes embodied. This is called the body of enjoyment, sambhogakāya. The full manifestations of forms, as clearly perceivable mental contents, are then called nirmannakāya, the radiating body. When the dharmakāya is experienced for the first time, it is not an experience involving the senses, not a sensory experience. This is always the same for the practitioner in the absorption. It is an experience in which thinking and sensory experience are not activated and awareness rests in awareness. However, this basic experience can also be realized in sleep, which is a common experience for advanced practitioners. It is called the clear light, the experience of clear light in deep sleep, where there is no body awareness, no sensory awareness, but full wakefulness, full consciousness.

CC-02: Thomas Metzinger refers to this clear light as "luminosity".

TLB-04: Yes, that is a better term. I also call it 'enlightening clarity' in my new texts.

CC-03: What exactly does that mean? It is also meant metaphorically, so to speak. The light metaphor is omnipresent and controversial in Buddhist literature.

TLB-05: That's why the light metaphor is so incredibly concise and appropriate in this sense. It has only one disadvantage: there is no light source. When you fall asleep, you have the feeling that your senses, your consciousness, becomes obscured, and you have a blackout at some point. Expressed in language, deep sleep and loss of consciousness is like switching off the light. In the noncomprehending consciousness of deep sleep, it seems as if an internal light is switched on. There are no contrasts, no perception of forms, only the absence of 
shadow. The best analogous phenomenon in nature is when you do not know where the sun is during the day. You can no longer locate its position, but it is daylight. In nature this would be a diffuse brightness because the sun's rays are not conspicuous. But this is a lame example because there is total luminosity. Subjectively, when it first happened to me, I thought that someone had turned on the light in the room. I confused it with a visual light experience. When I opened my eyes, everything outside was pitch black, but inside I had a feeling of total, clear alertness. However, the body is asleep, there is no thinking and no sensory perception. One is amazed at this state. This is what happens to beginners. You are amazed because you do not know it. This astonishment brings you into dualistic perception. "What's actually going on here?" Once you know this, you can linger in this state for hours. This is also referred to as luminosity in deep sleep. It is the term you find everywhere. I call it 'illuminating clarity' because I wanted to avoid the Latin term. On the inside, everything is illuminated.

MW-03: You just described it as a very active process. You said that you were surprised and thought about it, but at the same time you related it to deep sleep.

TLB-06: For practitioners this naturally presupposes that they are already conscious in their dreams and can no longer be deceived by their dreams, that there is already a wakefulness, and that it is easy to remain conscious in dreams. In the beginning, all this lucid dreaming, the practice of mahāmudrā, complete natural detachment, is learned while dreaming. Mahāmudrā, the great seal. Mahā means "great" and mudrā means "seal". Mahāmudrā is the completely detached, natural state of being, in which there is a consciousness of the intangible nature of all phenomena. Mahāmudrā, the seal, is the empty, intangible nature of all phenomena. This awareness of the transparent, intangible, process-like nature of all phenomena is present in mahāmudrā. Eventually this natural detachment expands more and more into deep sleep. I am no longer surprised, there is no more surprise, no more awakening and thinking, awareness rests in itself. There is no thinking, no conceptual thinking, and no thinking in images. It is also not a dream event or something like that, but-it is really difficult to describe-it is as if consciousness is aware of itself. This is one way to express this. It is a resting state of the mind in itself. It is so refreshing that short periods are enough to feel as refreshed as if you had slept a whole night. The nice thing is that I was able to achieve this state in the MRI machine while I was being examined by Stefan Schmidt and Ulf Winter. This state occurred while the EEG and MRI were operating. This means that it was finally documented in digital form. When I came out of the MRI machine, I was as fresh as a newborn baby or as one waking up from the most restful sleep. It was 10 to $15 \mathrm{~min}$ in which I stopped being in the senses and was in this clear openness. This can happen during any nap, during any meditation, day or night; it is a well-known phenomenon. This is the basic state, which we call the truth dimension or dharmakāya.

CC-04: Is this reduced state of being without sensory perception also a state of awakening?

TLB-07: Yes, it is. But it is only dharmakāya without sambhogakāya and nirmānakāya, that is, without the body of enjoyment and the body of emanation, without the two essential dimensions of reality that make communication possible.

CC-05: It is a state of awakening without the superimposition of intentional objects. It is pure experiencing without actually having to communicate with the world.

TLB-08: Yes, that is right. 
CC-06: This means that even in the ordinary state of being with sensations, as well as in your unusual state of communicative awakening, the other minimal state is implicitly present.

TLB-09: Right, it is embedded in it.

CC-07: It would probably be too scientifically demanding to concentrate on this complex communicative state of awakening. So, from a methodological point of view, I think it would make sense to first accept what is actually present in this minimal state and then to recognize how this underlies the other state.

TLB-10: Yes, I understand your way of thinking. But it seems that you are specializing on partial awakening. This awakening is fairly uninteresting. It is, so to speak, just one's own withdrawal from the world.

CC-08: I agree with you. I also consider it uninteresting because psychological or spiritual aspects are neglected. But it is interesting simply as an object of research.

TLB-11: The state is uninteresting because in this state of being devoid of stimuli or interaction, you will not find any qualities that you can identify as love, compassion, wisdom, or anything else.

MW-04: What do you mean by interaction?

TLB-12: In other words, without stimulation by sensory input, without situations that require an awakened response. That means you are absorbed, but you are disconnected from the world. We call this meditation without sensory stimulation. How can I explain this? It is very difficult. Examples exist. It is like reducing water to $\mathrm{H} 2 \mathrm{O}$, without salt, without movement, just the most rudimentary things.

CC-09: This is what I think the scientific study of consciousness is about. We want to isolate the essential phenomenal and neurophysiological properties to understand complex states.

TLB-13: Yes, it is as little nutritious as distilled water.

CC-10: That may be.

TLB-14: I provided evidence of such a state in the MRI study by Stefan Schmidt and Ulf Winter. Do not leave this valuable data unused. It is true that we still are not ready to analyze interactive states with medical-scientific, physical technologies.

MW-05: May I summarize? There are two states. One is the state without sensory perception ...

TLB-15: This is called dharmakāya, the body of truth, the basic state of being that all awakened beings experience and which is the essence of awakening. However, it does not exist as a constant phenomenon that this dharmakāya remains separate from sensory input and unrelated to others. One speaks of the three inseparable kāyas: dharmakāya, saṃbhogakāya, and nirmānakāya are always in threes. But in the initial basic experience of awakening, there is no sensory input. It is just like you, Cyril, said, this is a basic characteristic present in all experiences of awakening, no matter how interactive they are, it is always present.

MW-06: There is also the intertwining with sensory perception. Imagine someone who has been meditating for a year or two entering into what you described as the beginners' experience of awakening without sensory perception for the first time. But for an advanced person, this can intertwine with the sensory experience in one sitting.

TLB-16: Yes, it could be that this sensory experience is also recognized in its empty, selfless shunyata nature. Now I will go into this intertwining in a little more detail. The insight into the nature of one's own mind extends to all perceptions 
that appear in the mind. It is no longer only the inactive mind that has a basic vibrating condition in basic consciousness, but also everything that then appears, such as each individual thought, each sensory experience, all these are recognized as being of the same nature. This means, no intertwining with anything else. It is permeated by this basic consciousness. We must distinguish this non-dual, awakened state without sensory perception from the dual samādhis, called dhyānas. These are not the dhyānas which are experienced in śamatha. We are talking about something else. Because even there, there is immersion without sensory perception. They are numerous and very deep. They are absolutely still and can last forever. Fortunately, I have experienced them, but not all of them. I have experienced the four dhyannas. Of the formless dhyānas I have only experienced the first two or three. There are the form dhyannas and the formless dhyānas, which are all samādhi states in the dual world. It is important not to be deceived by the descriptions of meditators who think that these are states of awakening. This happened to me, and my teachers cured me of it. I thought that this was also an awakening, even twice.

MW-07: What is the criterion why this was not the awakening?

TLB-17: It is easy to know afterwards. In this state, one has not perceived the fine dual component of the subject-object relationship to one's own meditation. One simply has not perceived it oneself. You have feelings of "all space," "all awareness." One no longer feels his ego, because there is a feeling of "everything", of "oneness". If you look at it philosophically, it is easier to do than to understand. Subjectively, the feeling is as if the ego, the sense of self, had become one with the whole space of awareness, one with nature, one with everything. This is exactly where the subtle ego-feeling is hidden.

MW-08: Because it is still the becoming one, because the ego is still present. I may be one with nature, but my ego is still there.

TLB-18: The ego has expanded to such an extent that it can no longer be identified per se. In retrospect, when you exit such a state, you cling to those experiences and want to return to them, and that is different from when you awaken. In awakening there is no such retrospective holding on and clinging. You are amazingly free in this subjective and somewhat dual world. You needn't to tell others or need to convince anyone of this awakening. There is no more "I want", "I need", "I have something". There is no more fascination, but it can regenerate itself.

MW-09: Is it a bit like a mystical experience that people have when they feel completely unified with the world?

TLB-19: Most mystical experiences are still in the subtle dual realm, but the real mystical experience is awakening. We get along fantastically with the real mystics. The Christian mystics have had the same kind of initial experience of awakening. Some, even Christian mystics, have been able to interact with the world based on this experience of simple awakening without any sensory experience. As Meister Eckhart preaches, he was either very animated when preaching about his mystical experience or he was able to experience it while preaching. This may well be true. I would like to be assured that it was possible for him. At least his words indicate that he had this experience.

CC-11: However, Meister Eckhart describes these states on the phenomenological level negatively as the absence of something. Did his descriptions also contain positive phenomenal features?

TLB-20: Yes, he described them as God. That is the positive aspect.

CC-12: I meant positive phenomenal qualities. 
TLB-21: Well, phenomenal qualities. If you describe them in phenomenological terms, awareness is present.

CC-13: These are important aspects for me. You say awareness is present.

TLB-22: As well as clarity and a dynamic. It is not a static state. Even when the dynamic has no reference and is only like a vibration in itself. This experience is not that nothing takes place and there is therefore no time, but that nothing takes place other than this vibrating, clear awareness. It is a very stable state of being, but it is dynamic. Of course, it is not a stable state of being, but a completely reliable state of being. This is what is meant by "stable", namely that it is always the case, but it is, of course, dynamic in its actual progress. It is not stable in the sense of "unchangeable", but stable in the sense of "absolutely reliable, always like that." The constant accessibility, the constant availability, the constant dynamic - that is the reliability. The only reliable thing is change. You could put it that way. Change is always there, we can rely on it, and that is why it is stable. No thought emerges, no sensory perception, there is only a clear experience of one's own liveliness. Vitality can also be taken as a quality. Basically, we are talking about the non-dualistic, basic experience of being alive. It is alive. You know how you say you're alive in dualistic language. But how do you know? Vital awareness! It is the alert, vital potential of being able to perceive and be active at any time. The basic potentiality of being is experienced, and this is the clear sign that one is still alive. An experience takes place, but without reference to anything. The simplest way to experience this is a state of being, for example while sitting, where nothing is demanded of you, where you can completely let go, free yourself of all control mechanisms and forget yourself, where egotism is forgotten, is not reconstructed, and an open state of being can arise since nothing is demanded of this supposed ego and me, anyway. Therefore, the experience of awakening occurs in most people in situations where nothing is demanded of them. The experience is more likely to occur there, but not only there because there one can best lose and forget oneself. This is our field of practice, to create more possibilities in the encounter of this interdependence with greater accessibility.

MW-10: In other words, the state without sensory perception is the practice space or something like that enables one to become intertwined.

TLB-23: It is the training space of minimal challenge. That is why sleep is so useful. That is where there is only minimal challenge to experience the clear light, luminosity, or brilliant clarity.

CC-14: Then this luminosity is also present in sleep without being aware of an object.

TLB-24: Yes, that is the non-dual luminosity. In dreams, that is lucid dreaming. And that goes on until you enter the non-dual presence while asleep. There are many transitions. There are dual lucid dreaming and the non-dual luminous presence. You cannot be in a non-dual, lucid presence and then continue dreaming. That doesn't happen. It is just clear light with no dream content. It devolves from the dream experience to the non-dual clear light. Because the dream stops. No one believes in the dream any longer. It collapses, and there are no more aftereffects. You just end up in clear openness.

CC-15: The transition from dual lucid dreaming to the non-dual luminous presence in sleep is the elimination of the dream content. Is this clear light in non-dual luminous sleep identical to the clear light in the minimal state (in meditation) we discussed in the beginning?

TLB-25: Yes, it is identical. You may replace this word "clear light" with "nondual luminosity." 
CC-16: What would you say that non-dual and dual states of luminosity have in common and what don't they [have in common]?

TLB-26: What they have in common is that they are relaxed, although the degree of relaxation varies considerably. Relaxation is not as deep as in non-dual luminosity. What they have in common is that there are no complicated chains of thought; they are somewhat rudimentary. With non-dual luminosity there is no sensory perception; with dual luminosity there is sensory perception, but no commentary-only what it takes to return to relaxation. What they have in common is that they are not interactive, that is, there is no communication with other people.

CC-17: Since you just talked about communication, I would like to ask you a question about the communicability of these states of emptiness. How can this experience, whether sensory or not, be reflected in language? How can we talk about it? How can we communicate it?

TLB-27: You can talk about it by replacing the term "emptiness", "the void", with the term "ungraspable" or "intangible." This is a first good metaphor to bring the concept of emptiness linguistically closer to our present experience [of emptiness], because the experience is not that something is empty, but that it is intangible.

CC-18: I know about this occidental misinterpretation of emptiness as the absence of something that is spatial, like liquid in an empty cup. [points to the cup] But this is not the point, it is rather about the substance-ontological emptiness of the cup and of the water itself.

TLB-28: Exactly, but then the language goes on and flounders into such paradoxes as "emptiness is fullness." That's great! That is the fullness of experience, without anything being tangible in the experience.

CC-19: The phrase "emptiness is fullness, fullness is emptiness" is typical of Zen Buddhism.

TLB-29: Well, that's actually Nagarjuna, of course. That is Nagarjuna from the second century AD, "Emptiness is form; form is emptiness.", etc. Nagarjuna examines it from all angles, he goes through all aspects of the experience. He does not stay with the formation or the skandha, but he goes through all six groups of consciousness. Everything has this intangible quality. However, in this intangible quality there is a dynamic because it is a process. After all, a dynamic is not graspable, it has this flowing quality, emptiness has this flowing quality, this dynamic. And what comes next? Now we get to an exciting, modern concept: the space of all possibilities unfolds, the space of possibility, the sphere of potentiality. The sphere of potentiality is a modern term from psychology, psychotherapy, and, I believe, philosophy. It is the space where everything is possible and where the configuration shows in which direction it is possible to enter. This is the direct experience of emptiness from the positive perspective. This is how awakened people experience the world as the space of possibilities.

CC-20: You talked about the phenomenon in this reduced state without sensory impressions in which one has no experience of the world, no experience of the self, that there is a phenomenal quality present that could be described as a flickering or vibration. You alluded to this. Something is given, but it seems contradictory, because it seems to be simultaneously in both a non-static and a static state.

TLB-30: Yes, otherwise we'd be dead. That is the difference between being dead and alive. If there were no more perception, no more experience, there would be nothing. [laughs] Basically, we are talking about the non-dual basic experience of 
being alive. It is like the knowledge of being or becoming aware. One is aware that awareness continues to exist and can be activated at any time. Let me try something. Suppose we had a sixth sense. We had the five senses plus the mental sense, and we had a seventh sense. That would be the sense of one's own vitality or the sense of the "awareness potential". In other words, something that makes it clear beyond doubt that life goes on, but there is no content at the moment. And in this basic awareness, subject and object are not separated. I am not the observer of my experience, but it is like a clarity occurring from within. This is what is meant by alaya, the non-dual basic consciousness.

CC-21: The current discourse in philosophy refers to this rudimentary samādhi state of selflessness, to the experienced absence of distinction, to how one can experience this non-relational state and report it. Finally, this presupposes that there is some kind of a relation between an experiential position and something experienced. This is exactly the logical problem we wanted to discuss with you today, namely, how to be able to access, know and report on an experience without an experiential position?

TLB-31: Look, my first non-dual experience was at the age of 29 or 30. It was the third year of a retreat; maybe I was 33 years old. The experience was such that it was intertwined with an experience of the fourth dhyana. The experience began when my body no longer needed to breathe. The body had stopped breathing. I had obviously entered this non-dual state. Right now, we are talking about it retrospectively. As I gradually returned to duality in my retreat room in France, which had previously disappeared, the perception gradually returned, the perception of my body, the visual perception of space. As my perception slowly returned, inhalation also slowly returned. Now we could continue with the description of the experience, which was so profound that it changed me permanently, with all the effects that followed. But I cannot tell you anything about the time before that.

CC-22: That's the point! That means in transition and only in transition is experience possible.

TLB-32: Only in transition ...

CC-23: Only in the transitional phase. That is the crucial point.

TLB-33: ... therefore it is not interesting to ask people about it afterwards because they would speculate. Only the transition is interesting. During my life-it was 30 years ago, I'm now 59-I have always found myself in this transition. What is interesting is that when you are in interaction and communication, you can make statements. But the other experience, when I temporarily enter into a non-dual state of being without sensory perception, it cannot be experienced by posterity and remains an unnameable experience for me.

MW-11: Could one say there is still a memory of it, or there is no memory?

CC-24: This is an important question.

TLB-34: There is no memory of it, like how I would remember your visit now.

CC-25: Is it an experience at all?

TLB-35: You do not know how long it took. But it is an experience, that's for sure. It even transformed you, which means you are someone else after that. You clearly cannot be transformed without having an experience. But it was experienced on levels of consciousness that are beyond the reach of a dual, reflective memory. But it is there. A familiarity arose. Furthermore, fear of non-existence disappeared. These are incredible memory traces. The body, that is, the energy body in this non-dual, open state, experienced such a state of relaxation, there was no tension for a while. That is why you feel physically very, very refreshed and fit, as if you 
had a great sleep. The mind was completely without tension for a while and returned to its completely formable, completely malleable, basic fluid state. After this complete flexibility, when it is still active, new experiences arise which were not previously accessible. This means that the intellect also functions differently, and insights simply tumble in. This is because the completely open, flowing mind relates itself anew to what one has already heard and learned or what the senses perceive. Everything is seen in a new light. A certainty arose within me.

CC-26: In other words, if we wanted to describe and analyze this state, be it on a phenomenological or neuroscientific level, we would have to focus mainly on the transitional phase?

TLB-36: Is that your research background? Are you preparing a research project or what is the reason for the interview? In any case, it was a lucky chance that it happened. I do not know if I can do it again. It was incredibly challenging because the electrodes were placed in such a way that the MRI helmet pressed on them, and I had severe pain at the hairline, where the skull curves. First, I had to relax despite all this pain. It is also extremely loud in this damn thing, and I usually meditate sitting rather than lying down. At least I have already had this experience in deep sleep. Although I can also meditate lying down, this happens in deep sleep. This somehow, occurred after they had given me the last instruction; my mind seemed to have disengaged. In retrospect, I can remember having been awake the entire time, but there was no sense of time. I could not hear the MRT and felt no pain. They told me that, after our last communication, when I assumed that they had taken me out of the tube a minute later, 10 to $15 \mathrm{~min}$ had passed. Fifteen minutes which I did not experience as $15 \mathrm{~min}$. If I had had to guess, it would have been one minute at most. That is striking for someone who has such a good sense of time as I do. In retrospect, the lack of time orientation confirms that I was in such a state of mind.

CC-27: So, it is a conclusion.

TLB-37: Yes, a conclusion. A conclusion I could also draw because I was extremely refreshed when I came out of the tube. I was probably the most refreshed person in the room. They saw me, and I had a very refreshed face. I think they even took a picture of me. I did not look tortured at all, although what they did to me was blatant torture. The pain was intense. But when it was over, I felt so refreshed both internally and externally, without any sense of time, but with a feeling of "No, no, I didn't sleep, I wasn't asleep, I didn't fall asleep." That would have been difficult. The way we tackled it to relax the different senses. We went through them all successively and performed tasks for each of the senses: task—relaxed; task—relaxed; task—relaxed. Ulf's idea worked. Afterwards, I entered into a kind of rudimentary consciousness. This was exactly what he wanted, a kind of basic state of consciousness which differentiates the species from which the other states of consciousness can emerge. It was not just a samāahi. I would have recognized a dual samādhi because I have experienced them all before. In a state of dual samādhi, I would have had a trace of memory; I know that.

MW-12: Could one say the following? Would you answer the initial question we asked, "How is perception possible without a perceiver?" by saying that the philosophers' premise is wrong and that there is pure perception without a perceiver?

CC-28: When we formulate the question in this way, although we are aware from an ontological point of view that no perceiver exists? How can experience take place in a condition in which nothing in particular is experienced? But this question is independent of whether there is an phenomenal self? Rather, the question is, "How is it possible to witness and report on something if there is 
nothing experienced in the non-egoic state of emptiness?" The real question is not whether there is a self in the sense of an ontological instance, but to what extent it is possible to report on an experience when the non-egoic experiential system is contentless. The minimal samādhi state is characterized precisely by the fact that nothing is experienced.

TLB-38: Okay, the only way I can answer that question is: because of the consequences. This is what you have already concluded.

CC-29: That is the point: it is the consequences. The transition process also seems to be very critical. That is the actual main question, not whether there is an ego; that is irrelevant.

TLB-39: That means we can put aside the question of a subject. What we are interested in is: How do we notice when the experience takes place? Can we recognize it by the effects? That is one possibility. By the traces of memory? That is another possibility. If there are no memory traces, then the only thing we have is the consequences. There are other parameters to consider: Is there a state of being without consciousness? For example, loss of consciousness when people are knocked out, be it by an anesthetic, a shock, or an accident, or something else. Is that total loss of consciousness? What are these reduced states of consciousness? Consciousness apparently does not cease to exist, but it is not accessible to memory. There is not only the meditative state; there are many others. As a summary of Ulf's first results, Stefan told me that the state that they had recorded in my case, based on the signals represented there, does not correspond to deep sleep, to unconsciousness, or to the dream state, but actually documents a new state of consciousness.

CC-30: The basic hypothesis is that this state, which was isolated in MRI, is the underlying structure of every other state of consciousness.

TLB-40: Yes, if this could be proven physically, you would have to find something like oscillatory patterns that are overlaid by all other oscillatory patterns. As practitioners of awakening, we could say that this dimension of awakening permeates all other sensory experiences. It is also our experience that one can always immediately enter this experience. We call this-like the other side of the coin-co-emerging, the simultaneous emergence of samsāra and nirvāna. If you can open yourself to any state of mind where you enter the area of highest density, where you feel that there is the strongest tension, the strongest attachment to the ego, the experience of anger, wrath, sensory experiences, where you feel the supposed center, then this always leads to this centerless openness. In this way the underlying dimension is revealed.

\section{Focused Discussion of the In-Depth Conversation}

Theories of consciousness in Western philosophy tend to be theories that are not derived from meditation experience and are based primarily on abstract conceptions of consciousness that are, at best, informed by empirical evidence. In our view, the methodological value of deep meditation as a tool for exploring the epistemic goal, i.e., consciousness per $s e$, is often neglected in empirically and philosophically informed consciousness research. In developing a unified, coherent, and integrated theory of consciousness, we face a fundamental problem known as "epistemic asymmetry" [40]. There are two completely different ways of obtaining knowledge about consciousness. Throughout history, thinkers have pondered whether and how to relate introspective knowledge of consciousness from the first-person perspective to knowledge of consciousness from the third-person perspective. The more fine-grained the phenomenological and neurophysiological descriptions and analyses become, the better the two perspectives can be related to each other, especially in the case of "pure" consciousness as an object of research, since, here, the "noise" of non-minimal states of consciousness is "smoothed out", and, thus, only the essential fea- 
tures of consciousness are examined. For the first time, both neuroscientific data on "pure" consciousness (see [32]) and TLB's phenomenological descriptions are available from the same person and can now be related, an endeavor that is still in progress. In this sense, the present neurophenomenological paper makes a modest contribution to bridging to some extent the explanatory gap between the first-person subjective experience and the third-person neurophysiological data.

While it is not clear whether the study of the phenomenology and neural correlates of "pure" consciousness will pave the way to a deeper understanding of consciousness, it may reveal aspects of consciousness that cannot be explained by existing theories, which in itself is of significant epistemic value.

Through deep meditation, the epistemic target, consciousness per se, can be explored by disrupting subpersonal processes that underlie the phenomenal self ("selfless" states, e.g., [41], the subjectivity of consciousness ("non-duality"; e.g., [42]) and consciousness tout court ("absolute emptiness"):

Meditation can be seen as a special way of becoming aware of consciousness itself per se-yet not in the sense of an introspective observation of mental processes, but in the sense of consciousness precisely of consciousness itself. In the meditative state of mind one is simply aware of being conscious at the very moment, or, to be more precise: one experiences oneself as this very moment of consciousness. [17]

An important reason why TLB's statements about "pure" consciousness may seem incomprehensible to some readers, besides the lack of conceptual framework, is the constant shifting of the discussion between the levels of phenomenology, metaphysics, and soteriology. For this reason, we will attempt to clarify key concepts and their interrelationships by paraphrasing or explaining statements exclusively at the phenomenological level.

According to TLB, "pure" consciousness is an experience unrelated to sensory input and refers to the non-dual dimension of consciousness. Nonduality is a mode of consciousness in which the ordinary subject-object dichotomy is no longer experienced $[42,43]$. "Pure" consciousness is also called the basic experience of experiencing. Perhaps the most striking feature in phenomenological reports of "pure" consciousness, including the report of TLB, is the considerable extent to which nouns and adjectives are provided with negation prefixes and other forms of negation, indicating the absence of intentional content. The TLB description of "pure", selfless consciousness refers to a non-egoic, awake state without intentional content. "Pure" consciousness itself is not even characterized by a minimal phenomenal sense of selfhood, not even by a rudimentary subjective perspective of experience. The phenomenology of "pure" consciousness is characterized by the absence of an appearing self-centered world; it is an anonymous experience devoid of intentional content. The appearance of a world and a self is not given. The collapse of distinctions within the representational space is an indication of deep states of absorption from which intentional content is withdrawn.

But can an anonymous whose representational system operates in a non-standard configuration, in which neither a model of the self nor a model of the world is instantiated, even report this contentless experience? If there is no phenomenality, how is it possible to report on this condition? Does a phenomenology of emptiness really exist? Can the phenomenology of MPE be described and analyzed in a meaningful way without ending up in logical contradictions or a confusion of personal and sub-personal levels?

The construct of "pure" consciousness involves the performative paradox inherent to auto-phenomenological reports on selfless states, since knowledge presupposes the instantiation of an autobiographical model of the self. The knowledge that one has been in a selfless state cannot be integrated into the autobiographical self-model, which means that memories of it are necessarily post-hoc confabulations. TLB emphasizes that it is inherent in "pure" consciousness that the person who has been in that state cannot have any immediate knowledge of that state. 
Irritatingly, "pure" consciousness can refer to a state in which no phenomenal properties are instantiated. Thus, it can be trivially questioned whether this state represents an experience at all, or whether the integration of instantiated phenomenal properties into memory is inhibited. On the other hand, "pure" consciousness refers to a state in which at least one phenomenal property (e.g., "luminosity") is instantiated and held in memory, explaining reportability. Luminosity is also referred to as brilliance, self-radiance, brilliance, clear light, or self-illuminating clarity. The meaning of the term and its semantic obscurity represent a controversial point of contention, which has led to conflicting interpretations [44] (p. 1597). The concept of luminosity of consciousness goes back to Siddhartha Gautama, the founder of Buddhism, and is first found written down in the Anguttara Nikaya (1.49-1.52), more precisely in the Pabhassara Sutta: "Luminous [ . . ] is this mind, but it is defiled by adventitious defilements." [44] (p. 97) Metzinger [2,3] tentatively correlates luminosity with the phenomenal signature of arousal, as the predictive top-down model of the bottom-up ARAS signal.

However, it is precisely this vagueness and contradictoriness of phenomenological accounts that make it difficult to adequately describe and analyze the phenomenology of "emptiness." It is striking that TLB's descriptions oscillate between these two states, which may suggest that they overlap on a continuum and that the shifts are very subtle. Let us call these two states absolute emptiness and minimal emptiness. A phenomenology of minimal emptiness is nomothetically possible, but a phenomenology of absolute emptiness is logically impossible.

The question whether "pure" states of consciousness are possible at all is very controversial. There are irreconcilable differences of opinion about whether "pure" consciousness is logically and nomologically possible or whether consciousness per se can be experienced. For philosophers (e.g., [45-48]) who defend the notion of "pure" consciousness, a phenomenological constraint must be satisfied for it to emerge; that is, at least one feature must be instantiated at the phenomenal level, and at least one quale must be instantiated. The difference between "pure" consciousness sensu minimal emptiness and "pure" consciousness sensu absolute emptiness consists exactly in the fact whether or not this phenomenological constraint is satisfied. In the case of absolute emptiness, there is no answer to the question of what it is like to be in that state. In the case of minimal emptiness, there is a feeling of consciousness per se.

At its core, it is a matter of explaining how it can be possible that a non-sensory phenomenal property, a non-intentional quale (e.g., luminosity), can be instantiated in a state of "pure" consciousness. Moreover, the question arises whether the co-instantiation of two and no more than two arbitrary phenomenal qualia would already no longer constitute "pure" consciousness. Is it necessary to distinguish different kinds of minimal emptiness? Our discussion here focuses in particular on the central question that led us to seek out TLB; that is, how it is possible to report "pure" consciousness. TLB names at least two possibilities.

First, TLB describes the experience at the transition between absolute and minimal emptiness as a kind of ephemeral afterglow in the form of a maximally abstract phenomenal quality, namely luminosity, which justifies the conclusion of having been in a state of "pure" consciousness. While in the fragile state of transition, there is a phenomenal "afterglow," so to speak, of content-free mental activities that took place during the state of absolute emptiness. Sekida describes this type of afterglow as follows:

Some may ask the question: "How have you been able to acquire this knowledge? The condition you speak of seems to be pure subjectivity, which is not reflected upon, which is not perceived, which is not known, and which cannot be described. How do you explain it?" The answer, very briefly, is that this activity of the mind still resonates very briefly, so that immediately after I have been in that state, I can still catch an impression of it as it disappears. [translated from German by CC] [49] (p. 92) 
According to TLB, there is a second possibility of knowing that one was in a state of "pure" consciousness. This explanation is not a confabulation, but a plausible inference based on the experienced discontinuity of experiencing or the lack of memory of the experiential content:

These are incredible memory traces. The body, that is, the energy body, in this non-dual, open state, has gone through such a relaxation, there was no tension for a while. That's why you feel physically very, very refreshed and fit, as if you had had a great sleep. The mind was completely without tension for a while and returned to its completely formable, completely malleable, fluid basic state. From this complete flexibility, new experiences arise afterwards, where it still has an effect, which were not accessible before. This means that the intellect also functions differently and the insights flow in more extensively. This is because the completely open, flowing mind relates itself anew to what one has heard and learned before or what the senses perceive. Everything is seen as if in a new light. (see TLB-35)

According to TLB, "pure" consciousness is the basic experience of awakening that has the potential to transform one's consciousness so profoundly that it has far-reaching and lasting consequences for all subsequent everyday sensory experiences. Through repeated collision with the basic experience of awakening, the practitioner eventually reaches a point of no return, from which the phenomenal qualities instantiated during a state of "pure" consciousness gradually become integrated into everyday life as well and eventually become a trait of consciousness, until finally a stage of development called awakening is reached.

In summary, "pure" consciousness in the sense of absolute emptiness is a state that, according to TLB, cannot be reflected or interpreted. This type of mental activity supposedly continues to resonate during the transitional state of minimal emptiness and passes into everyday life, resulting in successive subtle mental changes that continuously transform what was once ordinary experiencing.

The experience of structural emptiness, that is, the non-appearance of a spatiotemporally fragmented world centered around a phenomenal self, is what is called "pure" consciousness. This structural emptiness includes both the absolute emptiness and the minimal emptiness.

Despite its spatiotemporal non-structuredness, MPE paradoxically does not exhibit an atemporal static but a kind of unidirectional succession of psychic moments integrated into one another:

It is not a static state. Even when the dynamic has no reference and is only like a vibration in itself. This experience is not that nothing takes place and there is therefore no time, but that nothing takes place other than this vibrating, clear awareness. It is a very stable state of being, but it is dynamic. Of course, it is not a stable state of being, but a completely reliable state of being. (see TLB-22)

In contrast, an awakened person's experience appears just as structured as a nonawakened person's ordinary experience, yet it is not centered around a phenomenal self ("non-duality") and includes salient structural features of consciousness (e.g., "luminosity", "vibration"). The phenomenal qualities experienced during the "pure" consciousness state turn into traits and superimpose on the "ordinary" experience. In everyday life, sense experiences of the awakened person are imbued with the qualities of "pure" consciousness but at the same time, like "pure" consciousness, are non-dual (cp. with [50]). A new basic mode of experiencing has emerged in which the structured but non-dualistic world is, as it were, "luminous" and "vibrating," a mode, that is, in which the fluidity of the experienced world and, with the experiencing of this fluid world, at the same time consciousness per ser is felt.

According to Metzinger [2,3], the phenomenal quality of luminosity is the correlate of the functional property of attention and the physiological property of alertness. However, luminosity can be understood as phenomenal intensity in the absence of non-structural 
properties of phenomenology. It is argued that the phenomenology of minimal emptiness is a distinct cognitive phenomenology of structural features of phenomenology (e.g., phenomenal intensity) in the absence of non-structural features of phenomenology. A structural phenomenal feature influences the overall phenomenology without being an experiential content [13] (p. 172). When a representational space is devoid of any sensory or mental input, a representational system operates in computational idleness, whereby structural features of phenomenology become attentively available and come to the phenomenal fore.

Since at least one basic nonstructural feature is considered a necessary condition for the existence of any phenomenology [13], it must be assumed that in the absence of sensorymediated nonstructural features, a mental system generates at least one maximal abstract nonstructural quality, which is derived from the structural properties of consciousness: The phenomenology of structural features is the correlate of the computational idleness of a mental system. A candidate for the simplest, maximally abstract phenomenal quality that a conscious system can instantiate is luminosity, for example.

However, another idea could be, due to sensory deprivation, the representational system begins to hallucinate the phenomenal quality of "luminosity", a phenomenon that might be expected to be understood as a correlate of underlying computational processes operating at idle in the absence of sensory input. For illustration, consider the Ganzfeld method, which involves quasi-“contentless" states, similar to descriptions of MPE [51]. While some types of Ganzfeld experiences may involve rich phenomenology, others more closely resemble descriptions of MPE and may be devoid of phenomenal content [14]. In contrast to sensory deprivation in MPE, the Ganzfeld method involves perceptual deprivation, i.e., uniform, moderately strong stimulation of sensory modalities, often the visual modality. Ganzfeld-induced states include fog- or mist-like phenomena, changes in experienced luminance, dissolution of boundaries between phenomenal units, and brief periods of "blankouts" in which subjects appear to have lost the ability to see [52-54]. In fact, some individuals describe an experience of "emptiness" or "nothingness" $[14,55]$. The transition between absolute emptiness and minimal emptiness in deep meditation seems to be comparable to the transition from a multimodal Ganzfeld-induced blankout to a multimodal Ganzfeld-induced quasi-contentless state instantiating luminous fog- or mist-like hallucinations. The transition between the two is tied to the satisfaction or non-satisfaction of the aforementioned phenomenal constraint. Another way to describe the transition is that it is accompanied by the instantiation of at least one (if there is such a thing at all) nonintentional, hallucinatory qualia such as luminosity. "Pure" consciousness contains mental properties that represent nothing, that are non-intentional but phenomenal. Block [56] referred to such "pure" sensations as "mental latex." Whereas absolute emptiness is the absolute absence of phenomenal content or the absolute non-reportability of phenomenal content, minimal emptiness is a state in which structural features of consciousness, otherwise implicit in the background of ordinary experience, become the reportable Gestalt, that is, the dominant feature of conscious experience itself.

In the state of "pure" consciousness, a state independent of sensory perception, the conscious representation of sensory data is suspended. Moreover, mental data that could be retrieved from memory or generated by mental operations, such as conceptual processing, are not consciously represented. The absence of "forms" corresponds to the omission of a consciously experienced representational spatial structure resulting from the maximal reduction of phenomenal items, turning structural features of consciousness (e.g., intensity) into salient, maximally abstract phenomenal qualities (e.g., "luminosity").

In the state of "awakening", structural and non-structural features of consciousness emerge equally as the gestalt, background, and foreground are superimposed. Thus, consciousness itself can be experienced not only during MPE but also in the state of awakening.

"Pure" consciousness can be instantiated both during meditation and sleep. In both cases, there is absolutely no or only minimal phenomenal content, but no conscious representation of sensory or mental content. In deep sleep, the senses fade, leading to a kind of blackout or blankout. According to TLB, it feels like turning off the lights. However, 
luminosity during sleep refers to an experience that occurs after falling asleep and before waking up. The phenomenon of lucid dreamless sleep (LDS), a variant of MPE in sleep, violates the naive axioms of everyday life, since both the phenomenal quality of wakefulness and its functional correlate, tonic alertness, are attributed only to being awake. In contrast, LDS is a kind of transitional state between an unconscious sleep state and a conscious waking state: a conscious sleep state similar to lucid dreaming but lacking dream content.

The transition from dual lucid dreaming to non-dual lucid presence in deep sleep is the elimination of dream content. The state of dreamless luminosity in deep sleep corresponds to the state of MPE in deep meditation. According to TLB, LDS is a state of luminosity without dream content. Thus, LDS is an experience during sleep that cannot be categorized as dreaming, but whose luminosity can arguably be reported after waking. In LDS or MPE, the intentional act of phenomenalization per se takes place but without intentional content, an act that Fasching [17] calls "pure" intentionality and describes as "'seeing' without a 'seer' separate from the 'seen"'. Patrizio Paoletti and Tal Dotan Ben-Soussan [57] have argued that intentionality is a necessary condition for consciousness without intentional content.

According to TLB, the acquisition of a sense of the subtle phenomenal qualities of awakening (e.g., luminosity) occurs at best during sleep, which is a mental training room in which it is minimally challenging to experience these qualities during the transition from absence of phenomenal experience to minimal phenomenal experience. The aim of this training is to refine the sensitivity to structural phenomenal qualities so that they can be experienced even under sensory impressions, i.e., that the sensitivity is transferred to everyday life.

It is important to understand that neither LDS nor MPE is a state of attentional inertia, nor are they identical with loss of consciousness; on the contrary, an essential feature of such a state is maximal attentional presence in the absence of an object of attention, most "luminous" awareness, as TLB makes clear:

Subjectively, when it first happened to me, I thought that someone had turned on the light in the room. I confused it with a visual light experience. When I opened my eyes, everything outside was pitch black, but inside I had a feeling of total, clear alertness. However, the body is asleep, there is no thinking and no sensory perception. (see TLB-05)

Luminosity may be the most basal phenomenal quality that becomes explicit and instantiated alone in the state of minimal emptiness. At the same time, however, intensity can be made explicit as an implicit structural feature of consciousness in a mode of being awakened as luminosity. The reportability of this basal quality seems to be possible after a state of "pure" consciousness sensu minimal emptiness, but not sensu absolute emptiness. Furthermore, reportability seems to be possible during the everyday experience of an awakened person but not in the everyday experience of non-awakened people.

The reportability of consciousness per se during everyday experience is present in the mystical dualistic state, where phenomenal experience has a dualistic configuration [58]. According to Stace [15], extrovertive mystical experiences are experiences where the external world is the focus of the mystical experience rather than the internal world of the person as in introvertive mystical experiences. It is this external world that is perceived by our senses, but in the case of an awakened individual in the mystical dualistic state, it is experienced as completely transformed. For example, the awakened individual experiences being united with the world, discovers its deeper meaning, and experiences luminosity.

According to Forman [58], the extrovertive state arises through repeated introvertive mystical experience, e.g., in sustained meditative practice (see [59]). Only after the introvertive experience of "pure" consciousness is habitualized does the capacity to witness consciousness per se in the dualistic mystical state emerge as a trait of consciousness. In order to achieve a deeper understanding of consciousness per se, phenomenological accounts of MPE should be taken seriously and used to heuristically inform theories of consciousness, as contemplative traditions have a substantial degree of analytic differentiation as 
well as a high practical knowledge of inducing altered states. To ignore contemplative traditions in the search for a theory of consciousness would be unphilosophical and culturally chauvinistic. It would be a lack of intellectual honesty not to take into account the innumerable reports on this issue simply because they contain mere epistemological intuitions and are obviously contaminated with metaphysical, epistemological, and soteriological presuppositions. Terms such as śūnyatā (emptiness) or samādhi (deep concentration) should be included in the research. However, the context-free siphoning off of "Far Eastern" terms into a "potpourri" merely reproduces the inherent logical connections and possible aporias of the respective consciousness-theoretical systems and at the same time undermines the progress of knowledge if they are semantically emptied. Thus, it is important to engage in genuine interdisciplinary and intercultural conceptual work.

Philosophical and neuroscientific research into "pure" consciousness is becoming increasingly important, but the subject is not yet receiving much academic attention. Scientists studying meditators like TLB are doing science, not a mystical practice, which may seem trivial, but the point is often missed and is perhaps one reason for the lack of attention. Studying mystical experience on a scientific basis does not make this scientific study mystical. However, the methodological difficulty of "contamination" mentioned above also applies to scientists themselves who study mystical experiences such as "pure" consciousness. Any philosophical and neuroscientific investigation of "pure" consciousness, including the present interview, will be colored by the specific belief system of the researchers. For example, the metaphysical framework for the majority of neuroscientists is materialistic.

While "all observations are interpretations in the light of theories" [60], and, thus, there can be no unbiased descriptions and analyses of "pure" consciousness, it is precisely the interdisciplinary and intercultural dialogue that offers the possibility to become aware of one's own theory-laden perspective as well as one's own "cognitive scotoma, a systematic blind spot in our thinking about ["pure"] consciousness" [61] and to take them into account in further research - this is probably the most epistemologically fruitful and epistemologically modest way. In a sense, we, a Buddhist lama with decades of practical experience, a cognitive neuroscientist, and a philosopher, have entered into a complex and difficult process of interdisciplinary and intercultural dialogue that relates, ironically as it may sound, to what is conveyed from the first-person perspective about an "anonymous perspective." Although this has its limitations for many reasons, we believe that this type of exploratory single-case study is valuable for neurophenomenology.

Author Contributions: Conceptualization, C.C., T.L.B. and M.W.; writing—original draft preparation, C.C. and M.W.; writing-review and editing, C.C., T.L.B. and M.W. All authors have read and agreed to the published version of the manuscript.

Funding: This research received no external funding.

Conflicts of Interest: The authors declare no conflict of interest.

\section{References}

1. Metzinger, T. The Ego Tunnel: The Science of the Mind and the Myth of the Self; Basic Books: New York, NY, USA, 2009; ISBN 978-0465-04567-9.

2. Metzinger, T. Minimal phenomenal experience: The ARAS-model theory: Steps toward a minimal model of conscious experience as such. MindRxiv 2019, 10, 38.

3. Metzinger, T. Minimal phenomenal experience: Meditation, tonic alertness, and the phenomenology of "pure" consciousness. Philos. Mind Sci. 2020, 1, 1-44. [CrossRef]

4. Bayne, T.; Hohwy, J.; Owen, A.M. Are There Levels of Consciousness? Trends Cogn. Sci. 2016, 20, 405-413. [CrossRef] [PubMed]

5. Dittrich, A. Ätiologie-Unabhängige Strukturen Veränderter Wachbewusstseinszustände: Ergebnisse Empirischer Untersuchungen über Halluzinogene I. und II. Ordnung, Sensorische Deprivation, Hypnagoge Zustände, Hypnotische Verfahren Sowie Reizüberflutung; 119 Tabellen; VWB-Verlag f. Wiss. u. Bildung: Berlin, Germany, 1996; ISBN 978-3-86135-456-7.

6. Windt, J.M. Altered consciousness in philosophy. In Altering Conscious. Multidiscip: Perspect. St.-Barbara CA Praeger; Greenwood Publishing Group: Santa Barbara, CA, USA, 2011; pp. 229-254. 
7. Khachouf, O.T.; Poletti, S.; Pagnoni, G. The embodied transcendental: A Kantian perspective on neurophenomenology. Front. Hum. Neurosci. 2013, 7, 611. [CrossRef]

8. Fasching, W. Intentionality and Presence: On the Intrinsic Of-ness of Consciousness from a Transcendental-Phenomenological Perspective. Husserl Stud. 2012, 28, 121-141. [CrossRef] [PubMed]

9. Christensen, M.; Welch, A.; Barr, J. Husserlian Descriptive Phenomenology: A review of intentionality, reduction and the natural attitude. J. Nurs. Educ. Pract. 2017, 7, 113. [CrossRef]

10. Metzinger, T. (Ed.) Grundkurs Philosophie des Geistes. Bd. 3: Intentionalität und Mentale Repräsentation; Mentis: Paderborn, Germany, 2010; ISBN 978-3-89785-554-0.

11. Metzinger, T. Being No One: The Self-Model Theory of Subjectivity; MIT Press: Cambridge, MA, USA, 2004.

12. Bayne, T. Conscious States and Conscious Creatures: Explanation in the Scientific Study of Consciousness. Philos. Perspect. 2007, 21, 1-22. [CrossRef]

13. Kriegel, U. Subjective Consciousness: A Self-Representational Theory; Oxford University Press: Oxford, UK, 2009; ISBN 9780199570355.

14. Forman, R.K.C. (Ed.) The Problem of Pure Consciousness: Mysticism and Philosophy; Oxford University Press: New York, NY, USA, 1990; ISBN 978-0-19-505980-9.

15. Stace, W.T. Mysticism and Philosophy; Macmillan: London, UK, 1960.

16. Choong, Y.M. Zum Problem der Leerheit (Śūnyatā) in der Prajñāpāramitā; Peter Lang: Bern, Switzerland, 2006; ISBN 978-3-631-53758-9.

17. Fasching, W. Consciousness, self-consciousness, and meditation. Phenomenol. Cogn. Sci. 2008, 7, 463-483. [CrossRef]

18. Josipovic, Z. Nondual awareness: Consciousness-as-such as non-representational reflexivity. Prog. Brain Res. 2019, 244, 273-298.

19. Josipovic, Z.; Miskovic, V. Nondual Awareness and Minimal Phenomenal Experience. Front. Psychol. 2020, 11, 2087. [CrossRef]

20. Milliere, R. The varieties of selflessness. Philos. Mind Sci. 2020, 1, 1-41. [CrossRef]

21. Metzinger, T. Précis of Being no one. Psyche Interdiscip. J. Res. Conscious. 2005, 11, 1-35.

22. Millière, R. Looking for the Self: Phenomenology, Neurophysiology and Philosophical Significance of Drug-induced Ego Dissolution. Front. Hum. Neurosci. 2017, 11, 245. [CrossRef] [PubMed]

23. Blanke, O.; Metzinger, T. Full-body illusions and minimal phenomenal selfhood. Trends Cogn. Sci. 2009, 13, 7-13. [CrossRef]

24. Metzinger, T. Why are dreams interesting for philosophers? The example of minimal phenomenal selfhood, plus an agenda for future research1. Front. Psychol. 2013, 4, 746. [CrossRef] [PubMed]

25. Picard, F.; Craig, A.D. Ecstatic epileptic seizures: A potential window on the neural basis for human self-awareness. Epilepsy Behav. 2009, 16, 539-546. [CrossRef]

26. Böhme, G. Bewusstseinsformen; Wilhelm Fink Verlag: München, Germany, 2014; ISBN 978-3-7705-5530-7.

27. Srinivasan, N. Consciousness Without Content: A Look at Evidence and Prospects. Front. Psychol. 2020, 11. [CrossRef]

28. Young, R.M. The mind-body problem. In Companion to the History of Modern Science; Olby, R.C., Ed.; Routledge: London, UK, 1990.

29. Chalmers, D. Facing Up to the Problem of Consciousness. J. Conscious. Stud. 1995, 2, 200-219.

30. Lama, D. On the Luminosity of Being. Available online: https://www.newscientist.com/article/mg17823965-100-on-theluminosity-of-being/ (accessed on 22 May 2021).

31. The MPE Project I Philosophisches Seminar. Available online: https://www.philosophie.fb05.uni-mainz.de/arbeitsbereiche/ theoretische/mpe/ (accessed on 1 June 2021).

32. Winter, U.; LeVan, P.; Borghardt, T.L.; Akin, B.; Wittmann, M.; Leyens, Y.; Schmidt, S. Content-Free Awareness: EEG-fcMRI Correlates of Consciousness as Such in an Expert Meditator. Front. Psychol. 2020, 10, 3064. [CrossRef]

33. Wittmann, M. Altered States of Consciousness: Experiences out of Time and Self; The MIT Press: Cambridge, UK, 2018; ISBN 978-0262-03831-7.

34. Jo, H.-G.; Wittmann, M.; Borghardt, T.L.; Hinterberger, T.; Schmidt, S. First-person approaches in neuroscience of consciousness: Brain dynamics correlate with the intention to act. Conscious. Cogn. 2014, 26, 105-116. [CrossRef]

35. Wittmann, M. Modulations of the experience of self and time. Conscious. Cogn. 2015, 38, 172-181. [CrossRef]

36. Ataria, Y. Where do we end and where does the world begin? The case of insight meditation. Philos. Psychol. 2015, 28, 1128-1146. [CrossRef]

37. Berkovich-Ohana, A.; Dor-Ziderman, Y.; Glicksohn, J.; Goldstein, A. Alterations in the sense of time, space, and body in the mindfulness-trained brain: A neurophenomenologically-guided MEG study. Front. Psychol. 2013, 4, 912. [CrossRef] [PubMed]

38. Droit-Volet, S.; Dambrun, M. Awareness of the passage of time and self-consciousness: What do meditators report? PsyCh J. 2019, 8, 51-65. [CrossRef] [PubMed]

39. Wittmann, M. Altered states of consciousness self and time during meditation. Int. J. Study Chan Buddh. Hum. Civiliz. 2020, 7 , 27-39.

40. Jackson, F. Epiphenomenal Qualia. Philos. Q. 1982, 32, 127-136. [CrossRef]

41. Letheby, C.; Gerrans, P. Self unbound: Ego dissolution in psychedelic experience. Neurosci. Conscious. 2017, 3. [CrossRef] [PubMed]

42. Millière, R.; Carhart-Harris, R.L.; Roseman, L.; Trautwein, F.-M.; Berkovich-Ohana, A. Psychedelics, Meditation, and SelfConsciousness. Front. Psychol. 2018, 9, 1475. [CrossRef]

43. Böhme, G. Meditation als Erkundung von Bewusstseinsformen. Paragrana 2013, 22, 88-99. [CrossRef]

44. The Teachings of the Buddha. In The Numerical Discourses of the Buddha: A Translation of the Angguttara Nikāya; Wisdom Publications: Boston, MA, USA, 2012; ISBN 978-1-61429-040-7. 
45. Albahari, M. Witness-Consciousness: Its Definition, Appearance and Reality. J. Conscious. Stud. 2009, 16, 62-84.

46. Thompson, E. Dreamless sleep, the embodied mind, and consciousness. In Open MIND; Metzinger, T.K., Windt, J.M., Eds.; MIND Group: Frankfurt, Germany, 2015; ISBN 978-3-95857-035-1.

47. Ramm, B.J. Pure awareness experience. Inquiry 2019, 1-23. [CrossRef]

48. Dainton, B. The gaze of consciousness. J. Conscious. Stud. 2002, 9, 31-48.

49. Sekida, K. Zen-Training: Das Große Buch über Praxis, Methoden, Hintergründe; Herder: Freiburg, Germany, 1993; ISBN 978-3-45104184-6.

50. Thompson, E. Waking, Dreaming, Being: Self and Consciousness in Neuroscience, Meditation, and Philosophy; Columbia University Press: New York, NY, USA, 2015; ISBN 978-0-231-13709-6.

51. Gibson, J.J. The Ecological Approach to Visual Perception; Houghton Mifflin: Boston, MA, USA, 1979.

52. Metzger, W. Optische Untersuchungen am Ganzfeld. Psychol. Forsch. 1930, 13, 30-54. [CrossRef]

53. Wackermann, J.; Putz, P.; Allefeld, C. Ganzfeld-induced hallucinatory experience, its phenomenology and cerebral electrophysiology. Cortex 2008, 44, 1364-1378. [CrossRef]

54. Schmidt, T.T.; Prein, J.C. The Ganzfeld experience-A stably inducible altered state of consciousness: Effects of different auditory homogenizations. PsyCh J. 2019, 8, 66-81. [CrossRef]

55. Vaitl, D. Veränderte Bewusstseinszustände: Grundlagen-Techniken-Phänomenologie; mit 11 Tabellen/Dieter Vaitl. Mit einem Geleitw. von Niels Birbaumer; Schattauer: Stuttgart, Germany, 2012; ISBN 978-3-7945-2549-2.

56. Block, N. Mental Paint and Mental Latex. Philos. Issues 1996, 7, 19-49. [CrossRef]

57. Paoletti, P.; Ben-Soussan, T.D. Reflections on Inner and Outer Silence and Consciousness Without Contents According to the Sphere Model of Consciousness. Front. Psychol. 2020, 11, 1807. [CrossRef] [PubMed]

58. Forman, R.K.C. What does mysticism have to teach us about consciousness? J. Conscious. Stud. 1998, 5, $185-201$.

59. Jones, R.H. Philosophy of Mysticism: Raids on the Ineffable; State University of New York Press: Albany, NY, USA, 2016; ISBN 978-14384-6119-9.

60. Westermann, R. Wissenschaftstheorie und Experimentalmethodik: Ein Lehrbuch zur Psychologischen Methodenlehre; Hogrefe Verlag: Göttingen, Germany, 2000; ISBN 978-3-8070-1090-8.

61. Metzinger, T. Suffering. In The Return of Consciousness: A New Science on Old Questions; Almqvist, K., Haag, A., Eds.; Axel and Margaret Ax:Son Johnson Foundation: Stockholm, Sweden, 2017; pp. 221-248, ISBN 978-91-89672-90-1. 